\title{
Intranasal Delivery of Proteins and Peptides in the Treatment of Neurodegenerative Diseases
}

\author{
M. Elizabeth Meredith, ${ }^{1,2,3}$ Therese S. Salameh, ${ }^{2,3}$ and William A. Banks ${ }^{2,3,4}$
}

\begin{abstract}
Received 31 October 2014; accepted 12 January 2015; published online 24 March 2015
Abstract. The blood-brain barrier (BBB) is a major impediment to the therapeutic delivery of peptides and proteins to the brain. Intranasal delivery often provides a non-invasive means to bypass the BBB. Advantages of using intranasal delivery include minimizing exposure to peripheral organs and tissues, thus reducing systemic side effects. It also allows substances that typically have rapid degradation in the blood time to exert their effect. Intranasal delivery provides the ability to target proteins and peptides to specific regions of the brain when administered with substrates like cyclodextrins. In this review, we examined the use of intranasal delivery of various proteins and peptides that have implications in the treatment of neurodegenerative diseases, focusing especially on albumin, exendin/GLP-1, GALP, insulin, leptin, and PACAP. We have described their rationale for use, distribution in the brain after intranasal injection, how intranasal administration differed from other modes of delivery, and their use in clinical trials, if applicable. Intranasal delivery of drugs, peptides, and other proteins could be very useful in the future for the prevention or treatment of brain related diseases.
\end{abstract}

KEY WORDS: blood-brain barrier; cognition; intranasal; memory.

\section{INTRODUCTION}

Research on intranasal delivery of drugs, peptides, and proteins has grown over the past decade as an alternate way to deliver these compounds to the brain. The blood-brain barrier (BBB) limits the ability of most biologicals to enter the central nervous system (CNS). Therefore, researchers have explored alternate routes to the brain, specifically intranasal delivery, as there are many benefits to intranasal administration compared to intravenous or oral paths. First, intranasal delivery of molecules provides a direct access to the CNS (1), without having to negotiate the BBB. Second, exposure of peripheral organs and tissues to the substrate is usually greatly reduced as most substances have a limited entry into the circulation, and therefore, systemic side effects are greatly reduced. Third, because substances do not have to reach the CNS through the circulation, those substances that have a rapid degradation in blood are not at a major

\footnotetext{
${ }^{1}$ Department of Pathology, University of Washington, Seattle, Washington, USA.

${ }^{2}$ Division of Gerontology and Geriatric Medicine, Department of Medicine, University of Washington School of Medicine, 1660S Columbian Way, 810A/Bldg 1, VAPSHCS, Seattle, Washington 98108, USA.

${ }^{3}$ Geriatrics Research Education and Clinical Center, Veterans Affairs Puget Sound Health Care System, University of Washington, Seattle, Washington, USA.

${ }^{4}$ To whom correspondence should be addressed. (e-mail: bankswa@slu.edu)
}

disadvantage as they are when given by intravenous administration (2). Fourth, there are indications that the intranasal route may allow biologicals to be targeted to specific regions of the brain (3-5). In addition, from a clinical therapeutic standpoint, it is well recognized that intranasal administration of drugs is non-invasive.

Despite these advantages, there are a few disadvantages that must be overcome. Intranasal delivery can cause a reaction in the nasal cavity, leading to irritation of the cells and nerves present within the cavity (6). In addition, there is limited absorption across the nasal epithelium (1), due to degradation by the nasal mucosa (7), the small surface area for absorption (6), and distance of transport or diffusion required to reach the target brain region. Targeting drugs to the cribriform plate rather than the turbinates would allow for decreased absorption by the circulation. Although there is criticism about the bioavailability of tested peptides and proteins within the CNS, there are current investigations working to improve uptake by the brain with intranasal administration, including PEGylation (8), cell penetrating peptides (9), and focused ultrasound (10). Furthermore, solid lipid nanoparticles have become an increasingly interesting way to prevent degradation and enhance absorption of the proteins and peptides on the mucosal surface (11). However, proteins and peptides directed specifically to the brain using this system need to be investigated more to verify transport into the brain rather than feeding into the lymphatic system and getting into the circulation. 
Peptides and proteins can enter the brain after intranasal administration directly or indirectly after coming in contact with the cribriform plate (Fig. 1). The anatomy of the nasal cavity and transport systems in place has been nicely reviewed elsewhere and should be consulted for a more detailed description of this pathway $(1,12,13)$. Indirect transport of molecules into the brain can also occur by first entering the vasculature or lymphatic system. However, once in the circulation, molecules must cross the BBB in order to reach the brain. More commonly though, there are two main direct pathways of entry to the brain after intranasal administration, the olfactory or the trigeminal pathway, as these pathways connect the nasal mucosa and the brain $(1,12)$. Some substrates can leak between the nasal epithelium through the intercellular spaces (Fig. 2a). There are also transcellular processes in which substrates are transported across the nasal epithelium by channels and pores or transcytosis (Fig. 2b, I/II). Membrane diffusion of lipidsoluble and smaller molecules can be achieved in an energyindependent manner depending on the physiochemical properties (Fig. 2b, III). Extraneuronal, intraneuronal, and transneuronal pathways can then be used to reach deep regions of the brain as summarized previously (5).

Intraneuronal transport occurs through axonal transport and usually takes more time (14). Because peptides are exposed to degradation through intraneuronal transport, it is most likely that intranasal peptides pass through intercellular clefts in the olfactory epithelium to eventually diffuse into the brain (15). This is also in agreement with the rapid delivery time of most peptides to various brain regions. Extraneuronal transport can occur via simple diffusion either through the interstitial fluid of the brain parenchyma or the cerebrospinal fluid (CSF).

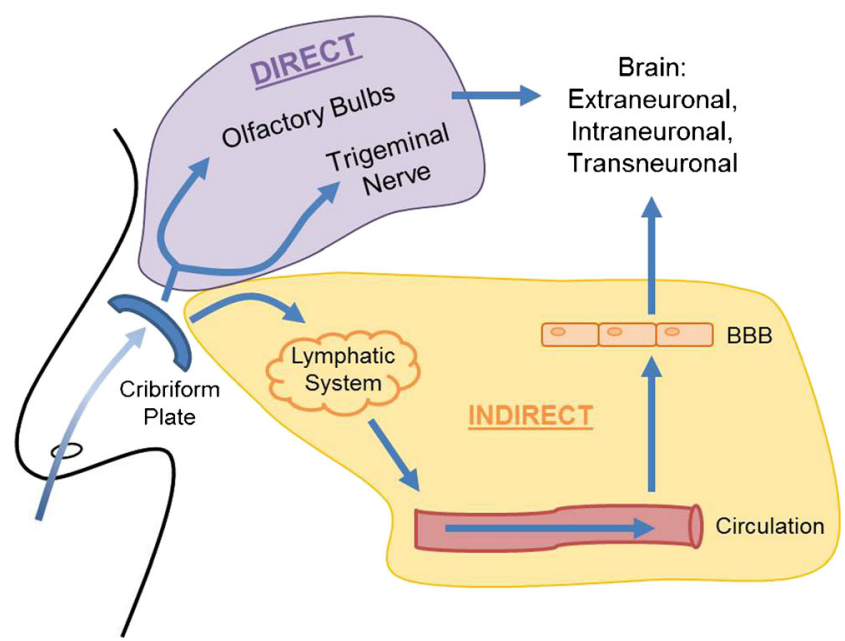

Fig. 1. Pathways for intranasal transport. Proteins and peptides delivered into the nasal cavity come into contact with the cribriform plate. The substrates reach the brain via direct and indirect pathways. The direct pathway can occur through the olfactory bulbs or trigeminal nerve. The indirect pathway transports the substrates into the lymphatic system, which then drains into the circulation. The proteins and peptides can then enter the brain if able to navigate the $\mathrm{BBB}$. Once in the brain, the substances are transported to various regions by extranueronal, intraneuronal, or transneuronal transport
Others have reviewed the intranasal delivery of a wide range of commercially available pharmaceuticals $(13,16)$. They highlight some of the kinetics involved in determining the transport rate of the various drugs after intranasal delivery. Here, we will discuss intranasal administration of several peptides and proteins known to aid in regulating feeding and energy expenditure and will describe the rationale for these substrates for improving memory and cognition (Table I). We compare intranasal administration to other routes including intracerebroventricular (ICV) and intravenous. We also review the current clinical field on the use of intranasal delivery of the specific peptides to the brain in the treatment of memory-related diseases.

\section{TARGETING PROTEINS AND PEPTIDES TO SPECIFIC REGIONS OF THE BRAIN TO ENHANCE THERAPEUTIC PROPERTIES}

Intranasal delivery of proteins and peptides to the CNS provides a means to bypass the $\mathrm{BBB}$ in the treatment of neurodegenerative diseases like Alzheimer's disease (AD). However, simply enabling them to enter the brain is not enough to ensure that it will have a beneficial effect on CNS functions such as cognition. In order to maximize the optimal response of the administered compound, it would be beneficial to target it to areas of the brain where it could exert the most significant effect on cognition, such as the hippocampus, and away from areas where it might exert unwanted actions.

One of the most successful approaches to target peptides to various regions has been the use of cyclodextrins. Cyclodextrins have long been used in nasal drug delivery as adsorption enhancing compounds to increase the intranasal bioavailability of protein and peptide drugs (32). There are several forms of cyclodextrins, including $\alpha$ (six glucose residues), $\beta$ (seven glucose residues), and $\gamma$ (eight glucose residues). In an experiment done examining the effect of three different cyclodextrins $[\alpha$-cyclodextrin, $\beta$-cyclodextrin, and (2-hydropropyl)- $\beta$-cyclodextrin (hydro- $\beta-C D)]$ on uptake of pituitary adenylate cyclase activating polypeptide (PACAP) after intranasal administration, the authors demonstrated a unique pattern of distribution for each of the cyclodextrins used (4). The $\alpha$-cyclodextrin increased uptake by the olfactory bulb and decreased uptake by the occipital cortex, striatum, and whole brain. $\beta$-Cyclodextrin increased uptake by all brain regions except the striatum and olfactory bulb. Hydro- $\beta-C D$ increased uptake by the thalamus and decreased uptake by the striatum. $\beta$-Cyclodextrin showed an increase in PACAP serum levels, while $\alpha$-cyclodextrin and hydro- $\beta-C D$ showed no change in serum levels. This indicates that $\beta$-cyclodextrin is capable of preventing PACAP from binding to uptake and clearance sites in peripheral tissue. These results demonstrated that various cyclodextrins could be used to target different proteins and peptides towards or away from certain regions of the brain. As a result, lower doses of the peptide can be used, and the effects would be localized to the regions where they would be most effective at altering CNS function (4).

Recent studies have also demonstrated the potential for albumin to aid in the targeting of peptides to various regions of the brain. In a study completed with leptin, a protein known to effect both feeding and cognition, albumin was able 
a Paracellular

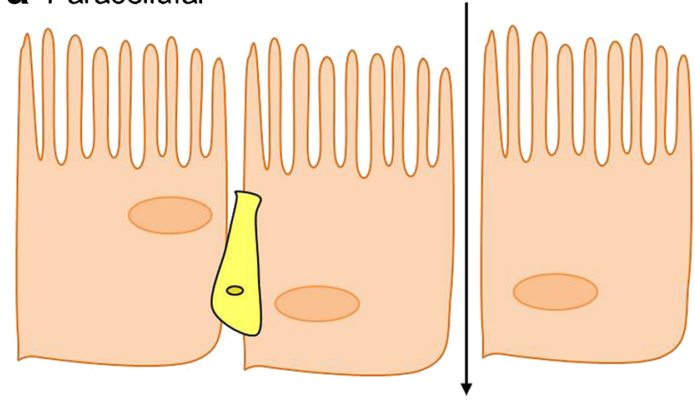

b Transcellular

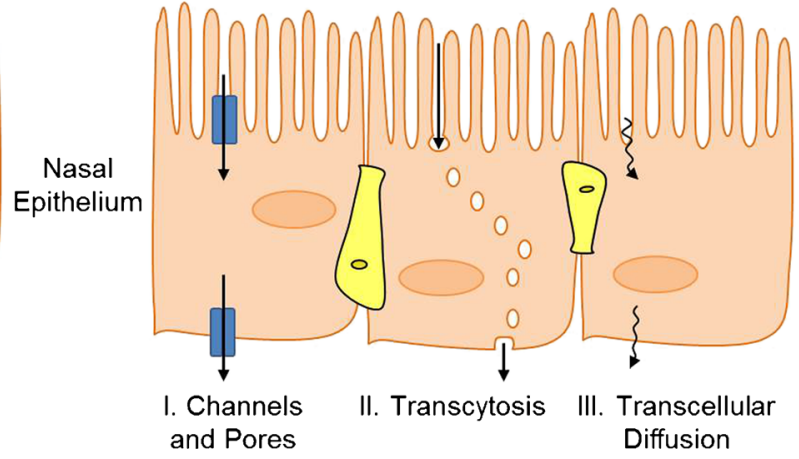

Fig. 2. Transport across the nasal epithelium. Transport across the nasal epithelium can occur by a paracellular transport in which proteins and peptides leak through the intercellular spaces. Transport through the cells can also occur in a b transceullar manner by specific $I$ channels and pores for the substrates, $I I$ transcytosis, and by $I I I$ transcellular diffusion depending on the physiochemical characteristics of the substrate

to alter leptin targeting after intranasal administration in a number of different ways to enhance its effects (3). First, albumin decreased serum levels of leptin by affecting its clearance from the brain. Second, it increased its uptake into the hypothalamus, a region of the brain that would enhance the effect of leptin on feeding and cognition. Third, it decreased uptake of leptin in regions of the brain like the cerebellum where it was not the directed target.

Together, these findings highlight the benefits of utilizing substrates such as albumin and cyclodextrins to aid in targeting peptides and proteins to the specific brain region of interest. This will be important in the treatments of diseases, which affect regions all throughout the brain.

\section{PROTEINS AND PEPTIDES}

\author{
Albumin \\ Albumin, the most abundant protein in the blood, is \\ emerging as a versatile transport molecule for targeted drug \\ delivery (33). Four main technologies that use albumin as a \\ drug carrier have been developed: physical or covalent \\ binding of the drug to albumin through a ligand or protein- \\ binding group, development of bispecific antibodies where \\ drugs are fused with albumin replacing the Fc fragment of \\ immunoglobulin $\mathrm{G}$, and encapsulation of drugs into albumin \\ nanoparticles (34).
}

These albumin-based technologies have been used successfully in the treatment of a number of diseases including diabetes and cancer. Levemir ${ }^{\circledR}$ and Victoza ${ }^{\circledR}$ are two drugs currently on the market for treating diabetes that use this albumin technology. Levemir ${ }^{\circledR}$ was developed by replacing the $\mathrm{C}$-terminal amino acid threonine in recombinant human insulin with a lysine moiety and then covalently binding myristic acid to its $\varepsilon$-amino group. Fatty acids such as myristic acid have an extremely high affinity for human serum albumin, which extends the half-life of Levemir® from 4 to 6 min for native human insulin to $5-7$ h (18). Abraxane ${ }^{\circledR}$, used in the treatment of solid tumors, is an albumin-paclitaxel nanoparticle. Abraxane $\AA$, while stable as a nanoparticle, dissolves rapidly after intravenous injection resulting in soluble albumin-bound paclitaxel complexes that are comparable in size to endogenous albumin. It is able to penetrate into tumors because of an albumin transport pathway mediated by the $60-\mathrm{kDa}$ glycoprotein gp60 (albondin) located on the endothelial cell surface of tumors (35).

Albumin transport pathways, such as those mediated by gp60, are found on the surface of endothelial cells in peripheral capillaries. However, brain endothelial cells have relatively low expression, and the $\mathrm{BBB}$ prevents albumin from crossing in vitro and in vivo. In order to bypass the BBB, recent studies show evidence for the uptake of albumin across the nasal epithelium $(3,17)$. Uptake occurred through a saturable transport system rapidly to all regions of the brain, with the highest levels detected in the striatum and the olfactory bulb.

Table I. Summary of Peptides/Proteins and the Intranasal Action

\begin{tabular}{|c|c|c|c|}
\hline Compound & Action & Intranasal effects & References \\
\hline Albumin & Transport molecules for targeted drug delivery & Alters delivery pattern and improves stability of substrates & $(3,17,18)$ \\
\hline Exendin & $\begin{array}{l}\text { Agonist for GLP-1 receptors leading to increased } \\
\text { insulin release }\end{array}$ & Decreases blood glucose levels & $(2,8,19)$ \\
\hline GALP & Regulates feeding & Decreases body weight & $(5,20,21)$ \\
\hline Insulin & Modulates glucose utlization & Improves memory in healthy and AD subjects within 1 week & $(22-25)$ \\
\hline Leptin & Anorexigenic satiety signaling factor & Decreases weight and food intake & $(26-29)$ \\
\hline PACAP & Regulatory peptide stimulating adenylate cyclase & Improves cognition & $(4,30,31)$ \\
\hline
\end{tabular}


Albumin-based technologies have been used for the successful clinical administration of a number of drugs such as Levemir ${ }^{\circledR}$ and Victoza ${ }^{\circledR}$, and albumin treatment has been tested clinically for acute ischemic stroke, although no clinical benefits have been found (36). However, with intranasal delivery, albumin seems to have a specific and selective pathway that differs from that of other peptides and proteins. Furthermore, albumin, when co-administered with various proteins and peptides, alters their pattern of delivery, which has the potential to enhance their function. Currently, there are no clinical trials examining intranasal delivery of albumin in the treatment of neurodegenerative diseases.

\section{Exendin}

Exendin is a glucagon-like peptide 1 (GLP-1) homolog and acts as an agonist for GLP-1 receptors. The GLP-1 receptor in the CNS mediates important effects on neuroprotection and cognition. Intranasal exendin improves neuronal survival (19). GLP-1 itself is a poor candidate for blood-tobrain delivery because it is rapidly degraded, whereas exendin is stable and crosses the BBB. Therefore, experiments have investigated the transport and action of exendin, as well as GLP-1, when delivered by the intranasal route.

GLP-1 receptors are present in hippocampus and coupled to signal transduction pathways involved in learning and memory, including the PI3K and adenylyl cyclase pathways (37). Activation of these receptors by GLP-1 agonists could aid in improving or maintaining learning and memory. Indeed, exendin-4 has profound effects on synaptic plasticity (38), decreases levels of $\beta$-amyloid (39), and protects synapses from $\beta$-amyloid toxicity (40).

Intranasal administration of exendin was four times more effective in delivery to the olfactory bulb, compared to intravenous administration (2). The delivery was quick, with a rapid uptake of exendin (9-39) 1 min after intranasal administration and was enhanced $60 \%$ by the use of cyclodextrins. However, the rest of the brain had similar uptake levels with either intranasal or intravenous treatment. The authors found that intranasal exendin was evenly distributed throughout the brain by the extraneuronal route via the CSF and Brownian diffusion. Ultimately, low levels of exendin actually reached the brain regions besides the olfactory bulbs, and these levels were indifferent between intranasal and intravenous delivery. Another study showed intranasal GLP-1 lowered blood glucose levels due to transport into the circulation, while the highly conserved residues of exendin, [Ser(2)] exendin(1-9), did not (19).

ICV injection of GLP-1 or [Ser(2)] exendin(1-9) and intranasal [Ser(2)] exendin(1-9) improved learning and memory as measured in the passive avoidance test and the Morris Water Maze (19). GLP-1 agonists enhanced long-term potentiation in the hippocampus, while the antagonist, exendin(9-39), prevented this improvement (40).

A recent report published in Diabetes Care found intranasal delivery of GLP-1 before every meal for 2 weeks recovered early phase insulin secretion and lowered glycoalbumin levels, suggesting improvements in the patients' diabetic symptoms (41). However, no cognitive tests were performed to determine if intranasal GLP-1 improved memory. On the other hand, there is a double-blind study currently being conducted with subcutaneous exendin- 4 in the treatment for early stage AD or mild cognitive impairment (MCI) (Clinical Trial NCT01255163).

\section{Galanin-like peptide}

Galanin-like peptide (GALP) is a 60-amino-acid neuropeptide primarily produced in the hypothalamic arcuate nucleus, while galanin has a wide distribution throughout the brain (42). Galanin and GALP are derived from two separate genes but share a 13-amino-acid sequence. GALP has complex actions on feeding behavior that vary across species $(20,21,43)$. In addition, GALP induces thermogenesis, altering energy balance (44).

A review of the literature failed to find any reports on the effect of GALP on cognition. However, the effects of galanin on memory and cognition have been reviewed in other manuscripts (45-47). Early on, it was thought that centrally administered galanin improved memory and cognition in rodents (48). More recently, it has been shown that these effects are dependent on dosing and location, as galanin has also been shown to result in performance deficits in memory and learning (49). Galanin has inhibitory actions on acetylcholine release in the ventral hippocampus, as well as inhibiting the release of several neurotransmitters worsening spatial and aversive memory and learning $(50,51)$.

Intranasal administration of GALP was 20-fold stronger in targeting the brain versus the periphery compared to intravenous and lead to large increases in the olfactory bulb within $10 \mathrm{~min}$ (5). Other brain regions at this time point contained similar increased levels of GALP, but not as great as the olfactory bulb. Intranasal administration of GALP with $\alpha$-cyclodextrins increased uptake in all brain regions by $2-3$ fold compared to GALP alone.

A small pilot study performed by Dr. Shioda's group showed that 1 week of intranasal GALP decreased body weight in humans (20). However, since then, there appears that larger studies have not been published linking intranasal GALP and changes in body weight, food intake, or cognition. Recently, Bertram and Tanzi (52) linked a single nucleotide polymorphism in the GALP gene that increases risk for developing AD by $10 \%$.

\section{Insulin}

Insulin has many important functions in the CNS. This includes modulating glucose utilization in the hippocampus and other brain regions, facilitating memory, and contributing to synaptogenesis and synaptic remodeling (53). Changes in brain insulin metabolism are thought to be the underlying cause of AD, a neurodegenerative disorder characterized by synaptic loss and memory impairment. Studies have shown that patients with AD have reduced insulin receptor sensitivity, hypophosphorylation of the insulin receptor, and downstream second messengers such as insulin receptor substrate-1 (IRS-1), and attenuated insulin and insulin-like growth factor expression (54). It has been hypothesized that increasing brain insulin concentrations in patients with $\mathrm{AD}$ would prevent or slow the development of this disease because enhancing brain insulin signaling improves memory processes 
in cognitively healthy humans and possesses neuroprotective properties (22).

Insulin crosses the $\mathrm{BBB}$ through a saturable transport system, that is influenced by a number of different factors including, but not limited to, the strain of mouse (55) and the brain region (56,57). About $0.05 \%$ of an intravenous-injected dose of insulin is taken up per gram of whole brain by the mouse $(56,58)$. This is slightly higher than that observed after intranasal administration, which peaks at $0.04 \%$ at $30 \mathrm{~min}$ (unpublished data). Despite the fact that insulin is capable of crossing the $\mathrm{BBB}$, peripheral delivery is not a viable therapeutic option as increasing the levels of insulin in the blood can induce hypoglycemia.

In healthy individuals, intranasal insulin administration improved performance on a declarative memory task based on a word list that had to be recalled both immediately and 1 week later (22). This type of memory is a hippocampaldependent function, and studies have shown that even a single dose of insulin can enhance these hippocampaldependent memory processes, in both spatial and working memory tasks.

Intranasal insulin administration has been shown to be an effective therapeutic treatment option for improving cognition in patients with AD. A pilot clinical study was completed on patients with AD or amnestic MCI (24). These patients received either placebo, 20 IU of insulin, or $40 \mathrm{IU}$ of insulin administered intranasally over the course of 4 months. In this study, they examined various outcome measures of memory, dementia, and daily living. Results from this study demonstrated an improvement in delayed memory and cognitive function and, importantly, also preserved the functional ability of the patients as estimated by caregiver rating, suggesting that the improvements were clinically relevant. A small group of patients in this study underwent a positron emission tomography (PET) study before and after they received the intranasal treatment. Based on the PET findings, the authors showed an increase in ${ }^{18} \mathrm{~F}$ fluorodeoxyglucose in the parietotemporal, frontal, precuneus, and cuneus regions of the CNS following intranasal insulin administration. This demonstrated that the enhancement in cognitive functioning observed in AD patients was linked to processes in those brain areas. Studies have shown that a single dose of intranasal insulin acutely improved memory in memory-impaired older adults with AD or MCI and also improved memory and cognitive function with multiple treatments of patients with $\mathrm{AD}$ and MCI (23). Insulin was effective in improving performance on a verbal memory test in a group of $\mathrm{AD}$ and MCI patients; however, within these groups, patients who were APOE 44 positive or female showed poorer recall following insulin administration compared to patients who did not possess this allele or were male (25).

\section{Leptin}

Leptin is a 146-amino-acid protein that is secreted by adipose tissue. It is an important peripheral satiety signal in which circulating levels correlate with body fat. Centrally, it is an anorexigenic factor, signaling in the hypothalamus to regulate feeding and energy expenditure. Leptin typically crosses the BBB in a saturable manner (59).
Leptin-receptor-deficient animals have impaired spatial memory (60). Indeed, leptin has been shown to improve learning and memory by activating NMDA receptors in the hippocampus $(61,62)$, in addition to increasing hippocampal synaptic density (63). In addition, leptin causes hydrolysis of triglycerides (64), potentially leading to improved memory due to decreased levels of triglycerides, a factor implicated in impaired cognition (65). Further, it has been suggested leptin decreases levels of $\beta$-amyloid in mice that overexpress this protein by inhibiting $\beta$-secretase activity (66).

Intranasal delivery of a synthetic leptin-like peptide is four times more bioavailable to the brain compared to subcutaneous, intraperitoneal, or intramuscular administration (26). Daily, intranasal leptin at concentrations of 0.1 or $0.2 \mathrm{mg} / \mathrm{kg}$ body weight has been shown to decrease weight and food intake over a 28-day period independent of changes in serum leptin levels (27). Radioactive tracer experiments reveal the hypothalamus and olfactory bulbs contain the greatest amounts of leptin 15-30 min after intranasal leptin administration $(3,28)$. The hippocampus also had increased levels, but these were not different from the total brain average.

ICV leptin reduces food intake, similar to intranasal, and enhances energy expenditure $(67,68)$. Continuous ICV infusion of leptin for 30 days led to an initial decrease in food intake but returned to normal by day 8 , despite decreased weight for the entire study (67), suggesting a change in energy expenditure. The dose of ICV leptin did not change the total amount of weight lost. However, larger doses led to more rapid weight loss. Hippocampal injections of leptin improved memory in an AD mouse model, the SAMP8 mice (62). These results were achieved with lower doses of leptin in 12month-old mice, while younger, 4-month-old mice required higher doses.

To date, there have been no human clinical trials performed investigating the effects of intranasal leptin administration on memory, food intake, or body weight.

\section{Pituitary Adenylate Cyclase Activating Polypeptide}

Pituitary adenylate cyclase activating polypeptide (PACAP) is a regulatory peptide that belongs to the secretin/glucagon/vasoactive intestinal peptide superfamily with two amidated forms, PACAP38 (38 amino acid residues) and PACAP27 (27 amino acid residues) (69). PACAP38, the predominant form, is found primarily in the hypothalamus, cerebral cortex, hippocampus, posterior pituitary, testes, and adrenals. Both PACAP27 and PACAP38 have been shown to stimulate adenylate cyclase release in a number of different cell types including pancreatic acinar cells, pituitary cells, neurons, and astrocytes $(70,71)$. Both in vivo and in vitro, PACAP38 has been shown to have potent neurotrophic and neuroprotective effects in neurotoxic, neurodegenerative, and ischemic models and has been proposed as a treatment for stroke, CNS injuries, and neurodegenerative diseases.

Use of PACAP as a therapeutic agent is possible because intravenous administered PACAP is transported across the BBB by a saturable transport system and uptake is highest in the hypothalamus and hippocampus (30). Problems with using PACAP as an intravenous therapeutic agent include is its rapid degradation in the blood and low bioavailability and, 
also, that a brain-to-blood efflux transporter exists, which limits the amount of PACAP present in the brain. To bypass these problems, intranasal administration of PACAP was used. Uptake of PACAP38 after intranasal administration occurs rapidly with the highest levels seen in the striatum and occipital cortex (4). The levels observed in the brain after intranasal administration are capable of exerting an effect on CNS function as observed after treatment of SAMP8 mice. In addition, daily intranasal treatment of PACAP for 3 months in another genetic AD mouse model, APP[V717I] transgenic mice, altered APP processing by increasing secretion of the neuroprotective sAPP $\alpha$ and improved cognition (31).

PACAP has been used in a number of clinical trials for treatment of a variety of disorders including migraines and depression (Clinical Trial NCT00944996) (72). A clinical study involving intranasally administered PACAP demonstrated a potential role for PACAP as a regulator of vascular smooth muscle, secretion, plasma extravasation, neutrophil recruitment, and cytokine activity (73). However, to date, no clinical trials have been performed on investigating the effects of intranasal PACAP on memory or cognition.

\section{Future Directions and Conclusion}

The use of an intranasal delivery system for peptides and proteins is promising in treating many neurological disorders, specifically memory and cognitive disorders. This method is advantageous in that it allows direct and rapid access to the brain for a variety of substrates, even for some, such as albumin, known to have a limited ability to cross the BBB. For patients, this method is relatively non-invasive and will limit side effects associated with peripheral administration of these substrates.

Getting substances into the brain has proved difficult because of the restrictive nature of the $\mathrm{BBB}$. Other routes of entry, such as intranasal administration, can help bypass this barrier. Modifications of molecules can improve both their delivery across the $\mathrm{BBB}$ and their uptake into brain by the nasal route, but the issue of bioavailability of these analogs needs to be addressed. The use of nanotechnology in delivering drugs to the brain is also a promising area and can package the proteins or enhance the permeation of the compounds across nasal mucosa (11). Detailed experiments describing the exact transport of proteins and peptides from the nasal cavity to the brain should be explored in the animal models. This will help improve transport systems and provide a more efficient access to the brain. In addition, clinical imaging of human nasal delivery will aid in the translation of animal work and is particularly needed as the nasal cavity anatomy varies greatly among species. As we advance in our understanding of the transport routes of these various proteins and peptides, we can begin to better target them to brain regions to enhance their effect.

\section{REFERENCES}

1. Lochhead JJ, Thorne RG. Intranasal delivery of biologics to the central nervous system. Adv Drug Deliv Rev. 2012;64(7):614-28.

2. Banks WA, During MJ, Niehoff ML. Brain uptake of the glucagon-like peptide-1 antagonist exendin(9-39) after intranasal administration. J Pharmacol Exp Ther. 2004;309(2):469-75.
3. Falcone JA, Salameh TS, Yi X, Cordy BJ, Mortell WG, Kabanov $\mathrm{AV}$, et al. Intranasal administration as a route for drug delivery to the brain: evidence for a unique pathway for albumin. Journal of Pharmacology and Experimental Therapeutics. 2014;351(1):54-60.

4. Nonaka N, Farr SA, Nakamachi T, Morley JE, Nakamura M, Shioda S, et al. Intranasal administration of PACAP: Uptake by brain and regional brain targeting with cyclodextrins. Peptides. 2012;36(2):168-75.

5. Nonaka N, Farr SA, Kageyama H, Shioda S, Banks WA. Delivery of galanin-like peptide to the brain: targeting with intranasal delivery and cyclodextrins. J Pharmacol Exp Ther. 2008;325(2):513-9.

6. Gizurarson S. Anatomical and histological factors affecting intranasal drug and vaccine delivery. Curr Drug Deliv. 2012;9(6):566-82.

7. Illum L. Nasal drug delivery-possibilities, problems and solutions. J Control Release. 2003;87(1-3):187-98.

8. Kim TH, Park CW, Kim HY, Chi MH, Lee SK, Song YM, et al. Low molecular weight $(1 \mathrm{kDa})$ polyethylene glycol conjugation markedly enhances the hypoglycemic effects of intranasally administered exendin- 4 in type 2 diabetic $\mathrm{db} / \mathrm{db}$ mice. Biol Pharm Bull. 2012;35(7):1076-83.

9. Khafagy E-S, Morishita M, Takayama K. The role of intermolecular interactions with penetratin and its analogue on the enhancement of absorption of nasal therapeutic peptides. Int J Pharm. 2010;388(1-2):209-12.

10. Chen H, Chen CC, Acosta C, Wu SY, Sun T, Konofagou EE. A new brain drug delivery strategy: focused ultrasound-enhanced intranasal drug delivery. PLoS One. 2014;9(10):e108880.

11. Almeida AJ, Souto E. Solid lipid nanoparticles as a drug delivery system for peptides and proteins. Adv Drug Deliv Rev. 2007;59(6):478-90.

12. Kozlovskaya L, Abou-Kaoud M, Stepensky D. Quantitative analysis of drug delivery to the brain via nasal route. J Control Release. 2014;189:133-40.

13. Pires A, Fortuna A, Alves G, Falcão A. Intranasal drug delivery: how, why and what for? J Pharm Pharm Sci. 2009;12(3):288-311.

14. Hanson LR, Frey WH. Intranasal delivery bypasses the bloodbrain barrier to target therapeutic agents to the central nervous system and treat neurodegenerative disease. BMC Neurosci. 2008;9 Suppl 3:S5.

15. Hallschmid M, Benedict C, Schultes B, Perras B, Fehm HL, Kern W, et al. Towards the therapeutic use of intranasal neuropeptide administration in metabolic and cognitive disorders. Regul Pept. 2008;149(1-3):79-83.

16. Mittal D, Ali A, Md S, Baboota S, Sahni JK, Ali J. Insights into direct nose to brain delivery: current status and future perspective. Drug Deliv. 2014;21(2):75-86.

17. Migliore MM, Vyas TK, Campbell RB, Amiji MM, Waszczak BL. Brain delivery of proteins by the intranasal route of administration: a comparison of cationic liposomes versus aqueous solution formulations. J Pharm Sci. 2010;99(4):1745-61.

18. Morales J. Defining the role of insulin detemir in basal insulin therapy. Drugs. 2007;67(17):2557-84.

19. During MJ, Cao L, Zuzga DS, Francis JS, Fitzsimons HL, Jiao X, et al. Glucagon-like peptide-1 receptor is involved in learning and neuroprotection. Nat Med. 2003;9(9):1173-9.

20. Shiba K, Kageyama H, Takenoya F, Shioda S. Galanin-like peptide and the regulation of feeding behavior and energy metabolism. FEBS J. 2010;277(24):5006-13.

21. Shioda S, Kageyama H, Takenoya F, Shiba K. Galanin-like peptide: a key player in the homeostatic regulation of feeding and energy metabolism? Int J Obes (Lond). 2011;35(5):619-28.

22. Benedict C, Hallschmid M, Hatke A, Schultes B, Fehm HL, Born $\mathrm{J}$, et al. Intranasal insulin improves memory in humans. Psychoneuroendocrinology. 2004;29(10):1326-34.

23. Reger MA, Watson GS, Frey Ii WH, Baker LD, Cholerton B, Keeling ML, et al. Effects of intranasal insulin on cognition in memory-impaired older adults: modulation by APOE genotype. Neurobiol Aging. 2006;27(3):451-8.

24. Craft S, Baker LD, Montine TJ, et al. Intranasal insulin therapy for Alzheimer disease and amnestic mild cognitive impairment: a pilot clinical trial. Arch Neurol. 2012;69(1):29-38.

25. Claxton A, Baker LD, Wilkinson CW, Trittschuh EH, Chapman D, Watson GS, et al. Sex and ApoE genotype differences in 
treatment response to two doses of intranasal insulin in adults with mild cognitive impairment or Alzheimer's disease. J Alzheimers Dis. 2013;35(4):789-97.

26. Novakovic ZM, Leinung MC, Lee DW, Grasso P. Intranasal administration of mouse [D-Leu-4]OB3, a synthetic peptide amide with leptin-like activity, enhances total uptake and bioavailability in Swiss Webster mice when compared to intraperitoneal, subcutaneous, and intramuscular delivery systems. Regul Pept. 2009;154(1-3):107-11.

27. Schulz C, Paulus K, Lehnert H. Central nervous and metabolic effects of intranasally applied leptin. Endocrinology. 2004;145(6):2696-701.

28. Fliedner S, Schulz C, Lehnert H. Brain uptake of intranasally applied radioiodinated leptin in Wistar rats. Endocrinology. 2006;147(5):2088-94.

29. Schulz C, Paulus K, Jöhren O, Lehnert H. Intranasal leptin reduces appetite and induces weight loss in rats with diet-induced obesity (DIO). Endocrinology. 2012;153(1):143-53.

30. Nonaka N, Banks WA, Mizushima H, Shioda S, Morley JE. Regional differences in PACAP transport across the blood-brain barrier in mice: a possible influence of strain, amyloid $\beta$ protein, and age. Peptides. 2002;23(12):2197202.

31. Rat D, Schmitt U, Tippmann F, Dewachter I, Theunis C, Wieczerzak E, et al. Neuropeptide pituitary adenylate cyclaseactivating polypeptide (PACAP) slows down Alzheimer's disease-like pathology in amyloid precursor protein-transgenic mice. FASEB J. 2011;25(9):3208-18.

32. Merkus FWHM, Verhoef JC, Marttin E, Romeijn SG, van der Kuy PHM, Hermens WAJJ, et al. Cyclodextrins in nasal drug delivery. Adv Drug Deliv Rev. 1999;36(1):41-57.

33. Kratz F. Albumin as a drug carrier: design of prodrugs, drug conjugates and nanoparticles. J Control Release. 2008;132(3):171-83.

34. Elsadek B, Kratz F. Impact of albumin on drug delivery-new applications on the horizon. J Control Release. 2012;157(1):428.

35. Schnitzer JE. gp60 is an albumin-binding glycoprotein expressed by continuous endothelium involved in albumin transcytosis. Am J Physiol Heart Circ Physiol. 1992;262(1):H246-H54.

36. Ginsberg MD, Palesch YY, Hill MD, Martin RH, Moy CS, Barsan WG, et al. High-dose albumin treatment for acute ischaemic stroke (ALIAS). Part 2: a randomised, doubleblind, phase 3, placebo-controlled trial. Lancet Neurol. 2013;12(11):1049-58.

37. Hölscher C. Drugs developed for treatment of diabetes show protective effects in Alzheimer's and Parkinson's diseases. Sheng Li Xue Bao. 2014;66(5):497-510.

38. Holscher C. Incretin analogues that have been developed to treat type 2 diabetes hold promise as a novel treatment strategy for Alzheimer's disease. Recent Pat CNS Drug Disc. 2010;5(2):109-17.

39. Perry EK, Kilford L, Lees AJ, Burn DJ, Perry RH. Increased Alzheimer pathology in Parkinson's disease related to antimuscarinic drugs. Ann Neurol. 2003;54(2):235-8.

40. Gault VA, Hölscher C. GLP-1 agonists facilitate hippocampal LTP and reverse the impairment of LTP induced by betaamyloid. Eur J Pharmacol. 2008;587(1-3):112-7.

41. Ueno H, Mizuta M, Shiiya T, Tsuchimochi W, Noma K, Nakashima N, et al. Exploratory trial of intranasal administration of glucagon-like peptide-1 in Japanese patients with type 2 diabetes. Diabetes Care. 2014;37(7):2024-7.

42. Juréus A, Cunningham MJ, Li D, Johnson LL, Krasnow SM, Teklemichael DN, et al. Distribution and regulation of galaninlike peptide (GALP) in the hypothalamus of the mouse. Endocrinology. 2001;142(12):5140-4.

43. Krasnow SM, Fraley GS, Schuh SM, Baumgartner JW, Clifton DK, Steiner RA. A role for galanin-like peptide in the integration of feeding, body weight regulation, and reproduction in the mouse. Endocrinology. 2003;144(3):81322.

44. Lawrence CB, Baudoin FM, Luckman SM. Centrally administered galanin-like peptide modifies food intake in the rat: a comparison with galanin. J Neuroendocrinol. 2002;14(11):85360 .
45. Beck B, Pourié G. Ghrelin, neuropeptide Y, and other feedingregulatory peptides active in the hippocampus: role in learning and memory. Nutr Rev. 2013;71(8):541-61.

46. Borbély E, Scheich B, Helyes Z. Neuropeptides in learning and memory. Neuropeptides. 2013;47(6):439-50.

47. Hökfelt T, Tatemoto K. Galanin: a multitalented neuropeptide. EXS. 2010;102:1-5.

48. Ogren SO, Kehr J, Schött PA. Effects of ventral hippocampal galanin on spatial learning and on in vivo acetylcholine release in the rat. Neuroscience. 1996;75(4):1127-40.

49. McDonald MP, Gleason TC, Robinson JK, Crawley JN. Galanin inhibits performance on rodent memory tasks. Ann N Y Acad Sci. 1998;863:305-22.

50. Yoshitake T, Yoshitake S, Savage S, Elvander-Tottie E, Ogren $\mathrm{SO}, \mathrm{Kehr}$ J. Galanin differentially regulates acetylcholine release in ventral and dorsal hippocampus: a microdialysis study in awake rat. Neuroscience. 2011;197:172-80.

51. Kinney JW, Starosta G, Holmes A, Wrenn CC, Yang RJ, Harris AP, et al. Deficits in trace cued fear conditioning in galanintreated rats and galanin-overexpressing transgenic mice. Learn Mem. 2002;9(4):178-90.

52. Bertram L, Tanzi RE. Genome-wide association studies in Alzheimer's disease. Hum Mol Genet. 2009;18(R2):R13745.

53. Banks WA, Owen JB, Erickson MA. Insulin in the brain: there and back again. Pharmacol Ther. 2012;136(1):82-93.

54. Talbot K, Wang H-Y, Kazi H, Han L-Y, Bakshi KP, Stucky A, et al. Demonstrated brain insulin resistance in Alzheimer's disease patients is associated with IGF-1 resistance, IRS-1 dysregulation, and cognitive decline. J Clin Invest. 2012;122(4):1316-38.

55. Banks WA, Farr SA, Morley JE. Permeability of the blood-brain barrier to albumin and insulin in the young and aged SAMP8 mouse. J Gerontol A: Biol Med Sci. 2000;55(12):B601-B6.

56. Banks WA, Kastin AJ. Differential permeability of the bloodbrain barrier to two pancreatic peptides: insulin and amylin. Peptides. 1998;19(5):883-9.

57. Banks WA, Kastin AJ, Pan W. Uptake and degradation of blood-borne insulin by the olfactory bulb. Peptides. 1999;20(3):373-8.

58. Banks WA, Jaspan JB, Huang W, Kastin AJ. Transport of insulin across the blood-brain barrier: saturability at euglycemic doses of insulin. Peptides. 1997;18(9):1423-9.

59. Banks WA, Kastin AJ, Huang W, Jaspan JB, Maness LM. Leptin enters the brain by a saturable system independent of insulin. Peptides. 1996;17(2):305-11.

60. Li XL, Aou S, Oomura Y, Hori N, Fukunaga K, Hori T. Impairment of long-term potentiation and spatial memory in leptin receptor-deficient rodents. Neuroscience. 2002;113(3):60715.

61. Shanley LJ, Irving AJ, Harvey J. Leptin enhances NMDA receptor function and modulates hippocampal synaptic plasticity. J Neurosci. 2001;21(24):RC186.

62. Farr SA, Banks WA, Morley JE. Effects of leptin on memory processing. Peptides. 2006;27(6):1420-5.

63. Oomura Y, Aou S, Fukunaga K. Prandial increase of leptin in the brain activates spatial learning and memory. Pathophysiology. 2010;17(2):119-27.

64. Steinberg GR, Bonen A, Dyck DJ. Fatty acid oxidation and triacylglycerol hydrolysis are enhanced after chronic leptin treatment in rats. Am J Physiol Endocrinol Metab. 2002;282(3):E593-600.

65. Morley JE, Banks WA. Lipids and cognition. J Alzheimers Dis. 2010;20(3):737-47.

66. Fewlass DC, Noboa K, Pi-Sunyer FX, Johnston JM, Yan SD, Tezapsidis N. Obesity-related leptin regulates Alzheimer's Abeta. FASEB J. 2004;18(15):1870-8.

67. Halaas JL, Boozer C, Blair-West J, Fidahusein N, Denton DA, Friedman JM. Physiological response to long-term peripheral and central leptin infusion in lean and obese mice. Proc Natl Acad Sci U S A. 1997;94(16):8878-83.

68. Levin N, Nelson C, Gurney A, Vandlen R, de Sauvage F. Decreased food intake does not completely account for adiposity reduction after ob protein infusion. Proc Natl Acad Sci U S A. 1996;93(4):1726-30. 
69. Arimura A. Pituitary adenylate cyclase activating polypeptide (PACAP): discovery and current status of research. Regul Pept. 1992;37(3):285-303.

70. Miyata A, Arimura A, Dahl RR, Minamino N, Uehara A, Jiang $\mathrm{L}$, et al. Isolation of a novel 38 residue-hypothalamic polypeptide which stimulates adenylate cyclase in pituitary cells. Biochem Biophys Res Commun. 1989;164(1):567-74.

71. Kimball BC, Mulholland MW. Pituitary adenylate cyclaseactivating peptide stimulates amylase release and cyclic adenosine monophosphate production in pancreatic acinar cells. Surgery. 1996;120(3):554-9.

72. Amin FM, Hougaard A, Schytz HW, Asghar MS, Lundholm E, Parvaiz AI, et al. Investigation of the pathophysiological mechanisms of migraine attacks induced by pituitary adenylate cyclase-activating polypeptide-38. Brain. 2014;137(3):779-94.

73. Kinhult J, Adner M, Uddman R, Cardell LO. Pituitary adenylate cyclase-activating polypeptide, effects in the human nose. Clin Exp Allergy. 2003;33(7):942-9. 